\section{Política externa e regime político}

LOPES, Dawisson Belém, Politica externa na Nova República: os primeiros 30 anos. Belo Horizonte, Editora UFMG, 2017. 284 páginas.

\section{Luiz Eduardo Garcia da Silva}

A política externa brasileira (PEB) deixou de ser tema exclusivo dos diplomatas e acadêmicos e hoje suscita o interesse de gama maior de indivíduos e grupos da sociedade civil. A inclusão de novos atores no processo de formulação das políticas públicas, fruto do amálgama social iniciado durante o processo de transição democrática, impactou também o campo da política externa. Daí emana o seguinte questionamento: qual é a relação existente entre a política externa e o regime político? Esse é o desafio empreendido pelo professor da Universidade Federal de Minas Gerais (UFMG) Dawisson Belém Lopes em seu livro Política externa na Nova República: os primeiros 30 anos.

$\mathrm{O}$ autor afirma que apesar de existir uma relação "inextricável" entre as duas categorias, tal abordagem foi ignorada pelos acadêmicos que reputavam naturezas distintas aos dois processos. As análises até então existentes se restringiam a verificação empírica da Teoria da Paz Democrática, que sustenta a ideia de que países que adotam o regime democrático tendiam a praticar uma política externa cooperativa, diminuindo a incidência de conflitos no nível sistêmico (Fearon, 1998; Saraiva, 2003). Lopes, por seu turno, propóe demonstrar a forma como as instituiçốes políticas domésticas são organizadas e a sua influência na formulação da PEB. De modo geral, o autor advoga que ocorrem paulatinamente a inclusão de novos atores, valores e práticas na ação internacional do Estado brasileiro.

Evidencia-se, assim, que a problemática levantada por Lopes difere daquela abordada previamente tanto no nível de análise quanto nos outputs que integram a política exterior. No nível de análise, o autor concentra o estudo nos condicionantes internos do Brasil e não na conformação da estrutura internacional. Já em relação aos outputs, ele analisa como a transição de regime político forçou paulatinamente a criação de mecanismos que democratizassem o processo decisório e de elaboração da PEB. Assim, a obra pode ser situada no campo de estudos das instituições políticas domésticas relacionadas ao processo de formulação da política externa (Faria, 2008; Figueira, 2009; Salomón e Pinheiro, 2013).

Mais do que apresentar respostas definitivas, o autor atesta sobre a necessidade de se entender o processo de formulação da PEB sob a égide de regimes políticos distintos. Nesse aspecto, ele retoma o debate acerca da exclusividade do Itamaraty em determinar a ação externa da nação especialmente após a instauração do regime militar, período em que diplomatas de carreira passam a chefiar o Ministério das Relaçôes Exteriores (MRE) com maior frequência. O discurso da chancelaria visa se distanciar dos assuntos internos utilizando a máxima de que a política externa configura um campo autônomo, narrativa consolidada haja vista a impressão positiva do modo como a PEB foi conduzida, inclusive entre políticos opositores ao regime. Por outro lado, Lopes adverte que esse discurso laudatório e aparentemente consensual pode também ser imputado à existência de um "silêncio respeitoso" decorrente de um ambiente com baixa participação política que é característico dos regimes autoritários.

À medida que o país se democratizava, a política externa ia a reboque, tendo de corresponder aos anseios de uma sociedade que apresentava maior diversidade de interesses. Pluralidade que se traduziu na inclusão de novos atores e princípios no tocante à formulação da política externa e que ensejou ao mesmo tempo maior contestação por parte daqueles grupos não contemplados em suas demandas. $\mathrm{O}$ caminho por maior democratização foi entendido como um processo de "poliarquização", nos termos estabelecidos por Robert Dahl (1971) e não seguiu um padrão linear apresentando avanços e recuos.

Os diferentes aspectos apresentados no livro são identificados a partir da forma como a obra está organizada: 1) "Transições dentro da transição"; 2) "Política externa, partidos políticos e processos eleitorais"; 3) "Novas e velhas práticas diplomáticas"; além da introdução e da conclusão.

O brasilianista e professor da Australian National University, Sean Burges, que assina o prefácio, identifica inicialmente a existência de uma crise na PEB cujo período corrente de redefiniçóes vincula-se espe- 
cialmente à "fragilidade institucional do Itamaraty". Burges assinala que o livro trata dos problemas estruturais dessa crise se referindo ao processo de desenvolvimento socioeconômico do país como deflagrador do aumento pelo interesse internacional dos atores políticos domésticos. Isso, por sua vez, forçou a burocracia diplomática brasileira a lidar com problemas outrora não competentes ao seu velho modo de agir (o que Lopes denomina de "formalismo").

Visando elaborar um texto mais leve, de caráter ensaístico e despido de pruridos formais, o autor introduz o texto traçando em poucas páginas a trajetória da PEB desde a Proclamação da República até os dias atuais. Contudo, seu objetivo não é apresentar a história da ação externa do Estado brasileiro, mas resumir a sua crescente complexidade após o início da distensão do regime militar. Dessa densidade fazem parte elementos inerentes ao regime democrático e que são discutidos em capítulos subsequentes, como a partidarização e a ideologização da política externa, a dificuldade do Itamaraty em se readaptar à atual conjuntura, os novos atores que integram o processo de formulação da PEB, a diplomacia presidencial, a conexão eleitoral da política externa e o papel dos partidos políticos, além de, por fim, a nova identidade internacional e o papel que o país pode e quer desempenhar no sistema internacional como portador de valores democráticos.

A primeira parte do livro ("Transiçóes dentro da transição"), composta de dois capítulos, trata dos entrechoques que o processo de formulação da PEB sofreu durante a transição democrática. $\mathrm{O}$ primeiro capítulo apresenta a trajetória da "redemocratização da política externa brasileira” desde o início da distensão do regime militar, no final da década de 1970, até o encerramento do governo Lula (2010). Afirma o autor que a restauração da democracia determinou câmbios na atuação internacional do Estado brasileiro em dois aspectos: 1) adotar e atuar de acordo com princípios condizentes aos do novo regime; 2) democratizar as instâncias formuladoras da PEB diminuindo a exclusividade e o insulamento do MRE sobre o tema. A política externa foi adquirindo um status de política pública pelos seus próprios formuladores. Uma política pública diferente, é verdade, mas ainda assim tendo de prestar contas à opinião pública e ao eleitorado.
A despeito do discurso de democratização da PEB ter sido mantido, a postura adotada pelo governo durante os mandatos de Fernando Henrique Cardoso relegou ao Estado a primazia de filtrar as demandas da sociedade civil de acordo com a conveniência para o interesse nacional. No governo Lula a política externa foi compreendida como uma política de Estado e de governo paralelamente. Isso significou que os agentes eleitos poderiam legitimamente imprimir sua identidade às açôes externas desde que não contrariassem os princípios de PEB estabelecidos na Constituição.

Em suma, a presença de novos "atores sociais e institucionais", com diferentes graus de influência, resultou em uma "agregação de interesses assimétrica" no campo da política externa, uma vez que alguns grupos possuíam mais recursos à sua disposição. Tal processo se assemelha ao que Bertrand Badie (2008) definiu como a "intrusão da sociedade". Como consequência surgiu uma avaliação não consensual acerca de como a política externa vinha sendo conduzida e formulada.

O segundo capítulo, escrito em coautoria com Mario Schettino Valente, aborda as condiçóes que possibilitaram a cristalização dos princípios de inserção internacional do Brasil, presentes no artigo $4^{\circ}$ da Carta Magna e no artigo $7^{\circ}$ do Ato das Disposiçóes Transitórias. Valendo-se da teoria pluralista, os autores analisam os constrangimentos em âmbito nacional e internacional que possibilitaram aos grupos de interesse pressionarem os constituintes. Em relação aos condicionantes internacionais são apontadas: 1) a pressão que os atores externos estatais e não estatais exerceram pela necessidade de se reforçarem políticas de proteção aos direitos humanos; 2) a promoção do desenvolvimento da tecnologia; 3) a necessidade de liberalização dos mercados a partir da atuação política dos Estados Unidos, FMI e Banco Mundial. Internamente é identificada a perda gradual da capacidade de controle do processo de democratização pelos militares. A conclusão apresenta quais grupos de interesse possuíram maior capacidade de influenciar o processo constituinte, escalonados em quatro estratos, dos mais aos menos influentes. No primeiro, encontram-se o Itamaraty e as Forças Armadas, que detinham melhores recursos e know-how para lidar 
com as açóes externas do Estado. No segundo, as entidades que defendiam bandeiras dos direitos humanos - Conferência Nacional dos Bispos do Brasil (CNBB) e Ordem dos Advogados do Brasil (OAB). Logo após, estão as entidades patronais, laborais e da burocracia econômica, entre elas o Ministério da Fazendo e o Banco Central. Por fim, o estrato com menor disponibilidade de recursos políticos é formado pelos movimentos sociais com demandas universalistas, como os movimentos LGBT, feminista, negro, ambientalista e socialista.

A segunda parte ("Política externa, partidos políticos e processos eleitorais") é composta de três capítulos e trata essencialmente da vinculação entre as instituiçôes políticas internas e a política exterior. O terceiro capítulo aborda o problema da partidarização e ideologização da $\mathrm{PEB}$, tema recorrente durante os anos em que o Partido dos Trabalhadores (PT) esteve à frente da presidência. A principal crítica refere-se ao fato de que o governo realizou uma política externa que privilegiou os interesses partidários em detrimento dos interesses nacionais. Assim, acusava-se a nova chancelaria de promover um distanciamento das linhas tradicionais de atuação internacional do país.

O autor relativiza essas críticas sustentando que divergências políticas e ideológicas sempre existiram no corpo diplomático brasileiro e que a PEB já não estava mais confinada exclusivamente à atuação do MRE, incluindo agora a participação de outros ministérios em sua formulação - a chamada "horizontalização da política externa”. Além disso, Lopes destaca que a inclusão de quadros partidários na burocracia pública não constituiu necessariamente uma novidade e/ou um problema em si. Em sua opinião, os riscos inerentes à essa prática são os mesmos presentes em qualquer outro órgão público: o descambe para o facciosismo ou o uso da coisa pública para interesses particulares. Porém, dentro de um contexto democrático e de ampliação de atores institucionais na formulação da política exterior, é de se esperar uma maior presença das agremiaçóes partidárias na condução da política externa.

O quarto capítulo aborda o tema da diplomacia presidencial realizada por FHC e Lula a partir dos conceitos de "autonomia pela participação" e "pragmatismo democrático", que caracterizaram a inserção internacional de seus mandatos respectivamente. O governo de FHC, desejoso de maior participação no sistema mundial, objetivou influenciar a agenda da política internacional se valendo de uma "lógica de adequação" ao contexto de aceleração da globalização. Nesse sentido, o câmbio no regime interno foi o promotor de uma inflexão na PEB que a permitiu a defender maior transparência e democracia do sistema internacional legitimamente. Já a política externa de Lula, embora não tenha rompido com os princípios daquela praticada anteriormente, apresentou caráter mais propositivo e contestador da ordem internacional, pressionando as grandes potências nos organismos multilaterais a adotar métodos mais transparentes e representativos nos seus processos decisórios.

No quinto capítulo, escrito em coautoria com Carlos Aurélio Pimenta de Faria, os autores analisam a importância conferida a política externa no contexto eleitoral, investigando se os eleitores observam alguma conexão entre o desempenho do governante nessa área e o seu nível de bem-estar individual. Afirmam que o prestígio internacional adquirido pelo Brasil explica o aumento gradativo no interesse pela questão ao longo das últimas campanhas. Se até 2010 o ambiente foi favorável ao governo incumbente, nas eleiçóes de 2014 o país já não lograva da fama positiva dos anos anteriores. Os candidatos desafiantes naquele pleito abordaram o assunto com o objetivo de arranhar a imagem da chapa liderada pelo PT. Os autores concluem esse capítulo sublinhando que os partidos políticos têm investido no tema da política externa em sua plataforma eleitoral. Se por um lado a referência a ação externa não garante votos, por outro pode ao menos afetar a imagem dos candidatos ou partidos adversários.

A terceira parte do livro trata das "Novas e velhas práticas diplomáticas". No sexto capítulo, o autor apresenta a tese do formalismo, desenvolvida por Alberto Guerreiro Ramos, aplicada ao caso da diplomacia brasileira. Ela descreve o esforço que as elites periféricas empreenderam ao tentar projetar uma imagem externa de seus países como nações avançadas e modernas, o que não condizia às suas realidades internas, e como o Itamaraty serviu de instrumento para materializar essa perspectiva. Se 
por um lado esse comportamento possibilitou a consolidação e a manutenção de alguns dos princípios de política externa por quase dois séculos, por outro levou a sociedade brasileira a questionar a adequação de sua diplomacia diante dos desafios reais que o mundo lhe apresentava. Outros aspectos desse formalismo se mantiveram ao longo do tempo, como a denúncia de ações discriminatórias contra negros, homossexuais e mulheres durante o processo de seleção de novos membros para compor o corpo diplomático. Tais práticas anacrônicas conflitam com a necessidade de um novo modelo de atuação diplomática mais bem adaptado às premências do regime democrático.

O sétimo capítulo aborda o tema da promoção externa das políticas sociais empreendidas pelo governo brasileiro. A emergência regional de governos contrários aos preceitos neoliberais vigentes durante a década anterior possibilitou ao Brasil assumir a liderança de um movimento que se contrapunha às diretrizes presentes no Consenso de Washington. Postulando uma gestão pública que manteve as variáveis macroeconômicas no centro do planejamento estatal, mas que as combinava com programas de inclusão social, transferência de renda e valorização do salário mínimo, o país se alçou com o representante de uma nova tendência chamada de "Consenso de Brasília”. O Estado brasileiro adotou durante os anos do governo Lula uma política externa inovadora e criativa, sabendo utilizar sua capacidade e boa reputação para influenciar uma tentativa de reordenamento do sistema internacional. Para tanto, serviu-se da diplomacia pública, estratégia que consiste em ampliar o escopo de atores responsáveis pela projeção internacional do país, incluindo diferentes agências estatais, ministérios e a própria Presidência da República.

O último capítulo do livro foi escrito em coautoria com Guilherme Casaróes e Carlos Frederico Gama e analisa o engajamento institucional do Brasil como potência média nos organismos multilaterais internacionais (ONU e instituições de Bretton Woods) durante e após a Guerra Fria. Essa middlepowermanship se traduz no uso do multilateralismo como meio de resoluçáo dos problemas internacionais e na assunção de um posicionamento de compromisso nos conflitos, fazendo com que a diplomacia se baseie na ideia de "boa cidadania internacional" (Cooper et al., 1993). Concluem os autores que o país apresenta um discurso que difere de sua prática, mas ressalvam que tais ambiguidades são frutos tanto das contradições internas do Brasil quanto daquelas existentes "entre as plataformas globais de São Francisco e de Bretton Woods” (p. 239). Além disso, o Estado brasileiro não possui poder suficiente que lhe permita agir como uma grande potência, abdicando de parte das regras estabelecidas pelos órgãos de governança global em detrimento de seus próprios objetivos ou interesses. Esse diagnóstico enquadra-se perfeitamente na "tragédia da política de potências médias em instituiçóes internacionais" (Cooper, Higgott e Nossal,1993).

No capítulo que conclui o livro o autor discute o caso do recuo da PEB durante os anos de Dilma Rousseff na presidência. Na visão de Lopes, a conjuntura pós-Lula não configurou um declínio em si, mas a correção da trajetória consolidada após a redemocratização e durante o governo FHC. O destaque e o prestígio internacional do país entre os anos de 2002 e 2010 denotam um momento distinto na projeção externa do país. Para comprovar que não se trata de um recuo, mas da retomada de um padrão "normal" de PEB, o autor apresenta alguns dados estatísticos sobre a atividade diplomática: média de viagens presidenciais por mandato; número de brasileiros eleitos para a direção de instituiçóes globais; vagas para provimento na carreira diplomática; salário inicial dos diplomatas; orçamento relativo do Itamaraty; e número de postos diplomáticos.

Assim, atesta-se que a obra cobre variados aspectos da relação entre regime político e a PEB. Convém lembrar que os capítulos que compóem o texto foram baseados em trabalhos prévios do autor, publicados em revistas científicas e/ou apresentados em seminários e congressos. Certamente, o livro tem o mérito de contribuir para o campo de análise de política externa no que se refere à importância dos condicionantes internos como componentes significativos para o processo de formulação dessa política pública. É interessante notar que a relação entre regime político e política externa não se restringe ao caráter plebiscitário ou referendário da democracia. Vigora, ainda, um processo de efetiva pluralização da $\mathrm{PEB}$, que vem permitindo 
a presença de novos atores em seu processo de formulação. Nesse sentido, Lopes convence o leitor de que o processo de democratização alterou a política externa do país tanto em seu processo de elaboração quanto em seu conteúdo. Ele destaca a inclusão de novas demandas e desafios à ação externa do Brasil, decorrentes da necessidade de se preservar e aprofundar aspectos democráticos das políticas públicas como transparência e representatividade. Por outro lado, trata-se de um processo ainda inconcluso e que merece a atenção dos cientistas sociais. Em suma, o livro de Lopes é fundamental para aqueles interessados em compreender o processo de formulação da política externa brasileira ao longo dos últimos trinta anos.

\section{Bibliografia}

BADIE, B. (2008), Le diplomatie et l'intrus. Paris, Fayard.

COOPER, A. F.; HIGGOTT, R. A. \& NOSSAL, K. R. (1993), Relocating middle powers: Australia and Canada in a changing world order. Vancouver, University of British Columbia Press.

DAHL, R. (1997), Poliarquia: participação e oposição. São Paulo, Edusp.

FARIA, C. A. P. de. (2008), “Opinião pública e política externa: insulamento, politização e reforma na produção da política exterior do Brasil”. Revista Brasileira de Politica Internacional, 51 (2): 80-97.

FEARON, J. D. (1998), "Domestic politics, foreign policy, and theories of international relations". Annual Review of Political Science, 1 (1): 289-313.

FIGUEIRA, A. R. (2009), Processo decisório em política externa no Brasil. Tese de doutorado, São Paulo, FFLCH-USP.

LOPES, D. B. (2013), Política externa e democracia no Brasil. São Paulo, Editora Unesp.

SALOMÓN, M. \& PINHEIRO, L. (2013), “Análise de política externa e política externa brasileira: trajetória, desafios e possibilidades de um campo de estudos". Revista Brasileira de Politica Internacional, 56 (1): 40-59.

SARAIVA, J. F. S. (org.). (2003), Foreign policy and political regimes. Brasília, Ipri.

\begin{abstract}
Luiz Eduardo Garcia da Silva, doutorando em ciência política, integra a linha de pesquisa "Instituiçóes políticas e estudos sobre elites” do Programa de Pósgraduação em Ciência Política da UFRGS. Atualmente é pesquisador visitante no German Institute of Global and Area Studies (GIGA), Hamburgo, Alemanha. E-mail: luizeduardogarcia1@gmail.com.
\end{abstract}

DOI: $10.17666 / 339617 / 2018$ 